\title{
Observantia et reverentia: respeitando um kantiano não ortodoxo
}

\author{
Observantia et reverentia: respecting a non-orthodox Kantian
}

\section{Darlei Dall'Agnol}

Doutor pela University of Bristol, Inglaterra, professor adjunto III da Universidade Federal de Santa Catarina, pesquisador do CNPq, Florianópolis, SC - Brasil, e-mail: ddarlei@yahoo.com

\begin{abstract}
Resumo
O presente trabalho presta homenagem a Valério Rohden, um dos mais importantes filósofos kantianos do nosso país, por meio de uma discussão sobre os diferentes tipos de respeito na filosofia moral de Kant. Primeiramente, o artigo procura mostrar que o grande tema filosófico que motivava as atividades investigativas de Rohden foi a questão da liberdade. Para ele, o próprio respeito é consciência da liberdade. Partindo da distinção entre observantia e reverentia, o artigo problematiza essa leitura de Kant. O trabalho, então, procura mostrar que Kant era, sob o ponto de vista metaético, um internalista e, por conseguinte, somente a própria lei moral pode ser motivadora da ação. Outros elementos, tais como o prazer, não podem a ela se misturar. Além disso, o artigo apresenta alguns pontos de concordância, mas outras diferenças interpretativas, entre o seu autor e o pensador aqui homenageado, sobre a questão do valor moral das ações na obra de Kant.
\end{abstract}


Palavras-chave: Respeito. Rohden. Kant. Valor das ações morais.

\section{Abstract}

This work honors the memory of Valério Rohden, one of the most important Kantian philosophers of our country, through a discussion of different kinds of respect within Kant's moral philosophy. First, this paper shows that freedom was the most important philosophical issue for Rohden, the one that motivated all his investigations. According to Rohden, respect itself is meant to be the consciousness of freedom. Morever, starting with the distinction between observantia and reverentia, this work problematizes this interpretation of Kant. It shows that, metaethically speaking, Kant was an internalist and, therefore, only the moral law could motivate the action. Other elements such as pleasure cannot mixture to the moral law. Besides that, the paper presents some agreements points, but also other differences between its author and Rohden in the interpretation of the moral value of actions in Kant's work.

Keywords: Respect. Rohden. Kant. Moral value of actions.

Valério Rohden é conhecido, no Brasil e no mundo, como um dos grandes tradutores das obras de Immanuel Kant para a língua portuguesa, principalmente das três obras Críticas (vide referências na bibliografia), o que já é suficiente para tornar merecida a presente homenagem feita pela Revista de Filosofia Aurora. Todavia Rohden não foi, se bem o conheci, apenas um tradutor ou um simples exegeta da filosofia de Kant. Não, certamente, um comentador qualquer. Ele foi, acima de tudo, um intérprete crítico motivado pelas suas próprias inquietações filosóficas. Portanto, a presente homenagem, organizada por Daniel Omar Perez, torna-se ainda mais justa.

Acredito que existia uma pergunta filosófica de fundo na vida de Valério e que, de alguma forma, estava expressa no seu questionamento crítico de Kant: "Por que a liberdade sem lei seria um absurdo, ou por que a liberdade tem que ao mesmo tempo conter uma lei que a ordene e regule?" (ROHDEN, 1981, p. 133). Valério, defensor de uma filosofia da liberdade, viveu e morreu apaixonado pela liberdade. Tornou-se, na bela expressão de Gerard Lebrun (1981, p. 14), um "kantiano de esquerda" ou, em outros termos, um kantiano não ortodoxo. 
A minha homenagem póstuma a Valério Rohden deve partir da melhor lembrança que tenho dele. Deixando de lado as suas aulas na Pós-Graduação em Filosofia da UFRGS no início da década de 1990, onde aprendi Kant, especialmente as suas discussões sobre a melhor tradução de alguns termos e passagens da Crítica da Faculdade do Juízo, e a posterior convivência em encontros sobre Kant, principalmente em Itatiaia (RJ), em 2001, no III Congresso Kant Brasileiro (quando orgulhosamente apresentou erros na edição original da Kritik der praktischen Vernunft - lembro da sua longa discussão sobre nur e nun - e em São Paulo, em 2005, quando organizou com outros eminentes kantianos brasileiros, Guido de Almeida e Ricardo Terra o X Internalionalen Kant Kongress), talvez a lembrança mais marcante que guardarei dele seja a de sentir-me especial na sua presença aqui no PPGF da UFSC nos últimos cinco anos de sua existência, de me sentir valorizado e, acima de tudo, respeitado. Foi a sua súbita morte que me fez perceber que me sentir respeitado por Valério era graças ao fato de que ele era uma pessoa especial que respeitava aqueles a sua volta. Para homenageá-lo, então, pretendo discutir a importância do respeito na ética de Kant dando continuidade a um debate sobre tipos de respeito que tivemos numa mesa-redonda, em 2007, no I Encontro do CIK, o Centro de Investigações Kantianas, que ele criou aqui em Florianópolis, e que deverá ser rebatizado como "Centro de Investigações Kantianas Valério Rohden". Essa parece ser uma boa forma de tentar compreendê-lo um pouco mais e, desse modo, continuar a honrar e a respeitar a sua memória.

Um dos pontos não ortodoxos da leitura de Rohden da filosofia prática de Kant, já claramente expresso no seu livro Interesse da Razão e Liberdade, consiste exatamente na sua interpretação do objeto próprio do respeito. Na seção 8.2, intitulada "Respeito pela liberdade", Rohden sustentou que "o respeito é, pela consciência da lei moral, a autoconsciência da nossa liberdade, tanto negativamente enquanto consciência da nossa independência de determinações das inclinações, como positivamente enquanto consciência da nossa autonomia como razão universalmente autolegisladora" (ROHDEN, 1981, p. 81) Na realidade Kant não fala em "respeito pela liberdade", mas no respeito pela lei moral. Como veremos, nada mais pode motivar o agente para que a ação tenha valor moral. 
A última discussão filosófica que tive com Valério, numa aula conjunta de Ética II no PPGF da UFSC, em 13/09/2010, seis dias antes de sua morte, foi exatamente sobre esse ponto. Como é sabido, Valério estava traduzindo a Antropologia e, contra a sua tentativa de amenizar o rigorismo kantiano, sustentando que há incentivos para o agir moral, por exemplo um certo sentimento de prazer no cumprimento do dever, sustentei que, sendo Kant claramente um internalista em metaética, a lei moral era suficiente para determinar a vontade. O contentamento no cumprimento da lei moral é apenas um efeito e não pode contar como causa determinante da vontade. Não pode haver, para Kant, nada antes ou junto com a lei moral. Do contrário, a ação perderia seu valor moral. Voltarei a esse ponto no fim do presente ensaio.

Na Ética de Kant, o cumprimento do dever pelo dever, condição necessária e suficiente do valor moral das ações, causa "dano a todas as nossas inclinações", uma certa "humilhação" ao amor-próprio dos agentes humanos, "abate a presunção" e, pace Rohden, um certo sentimento de desprazer, até mesmo de "dor" a partir da percepção da obri-

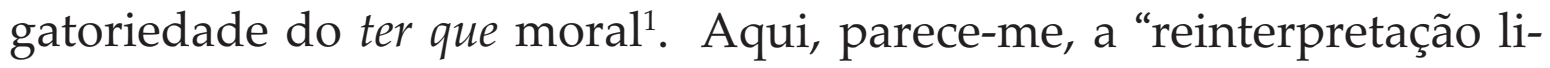
bertária" de Rohden (para usar outra feliz expressão de LEBRUN, 1981, p. 1) não faz juz à Ética de Kant, mas está sendo antes influenciada por um existencialismo do tipo sartreano (cf. ROHDEN, 1981, p. 111. para confirmar este ponto).

Talvez o próprio Kant não seja exatamente kantiano nos termos de Rohden e, certamente, eu pareço um kantiano ortodoxo, pois penso que o rigorismo moral de Kant não pode ser amenizado como queria Valério. Não sou um kantiano ortodoxo e tenho defendido uma transformação da Ética de Kant para que sirva no mundo atual, e isto é, evidentemente, algo que Kant não concordaria e, por conseguinte, aproximo-me de alguma forma da não ortodoxia de Valério. Seja como for, o ponto que discordei de Valério foi o de que sentimentos morais, mesmo o respeito pela lei moral, ou o contentamento no cumprimento do dever, a simpatia etc. tenham qualquer relevância no estabelecimento

1 (Cf. as expressões entre aspas na seção “Dos motivos da razão prática pura” em KANT, I. Crítica da razão prática. Tradução de Valério Rohden São Paulo: Martins Fontes, 2002. p. 114-144). 
do valor moral da ação em Kant. Há algo, todavia, que aprendi com Valério sobre respeito que gostaria de apresentar aqui.

Para começar, convém esclarecer a distinção entre tipos de respeito feita por Kant, principalmente, entre observantia e reverentia que apresentei na referida mesa-redonda. Para o autor da Metafísica dos Costumes, há dois tipos básicos de respeito:

1) o respeito que eu devo ter pelas outras pessoas ou que elas podem exigir de mim e eu delas (Observantia debita);

2) a reverência pela lei moral e não pelas outras pessoas (Reverentia adversus hominem) (KANT, 1968, p. 606-607).

Essas diferenças entre observantia e reverentia não podem passar despercebidas para interpretarmos bem a Ética de Kant, seja para transformá-la mantendo um espírito kantiano, seja para abandonar o seu caráter rigorista, ou seja, a ideia do puro "dever pelo dever"3.

A observantia, enquanto forma de respeito, é devida entre as pessoas por ser o reconhecimento da dignidade de uma existência que é um fim em si, isto é, de um valor que não possui equivalente, que não pode ser reduzido a um preço. Há, entretanto, diferentes formas de mostrar algum tipo de respeito aos outros dependendo de certas relações contingenciais, por exemplo, diferenças de idade, sexo, posições sociais tais como de uma autoridade etc. Alguém poderia respeitar Valério Rohden como um grande tradutor das três obras Críticas de Kant para a Língua Portuguesa, embora não como um filósofo. Ora, o respeito enquanto observantia parece conter tanto a ideia de uma admiração, quanto do reconhecimento da pessoalidade de um ser racional. Mas tal respeito dirige-se sempre a pessoas, nunca a coisas. Parece não fazer sentido dizer que respeito uma caneta, embora, certamente, o respeito mútuo seja devido entre pessoas. Como Kant exemplifica na

2 Ver também a Seção II da Parte II (Deveres de virtude para com os outros) da Doutrina da Virtude: sobre os deveres de virtude em relação aos outros seres humanos originados pelo respeito a eles devido. (KANT, I. Die metaphysik der sitten. Frankfurt: Suhrkamp, 1968. p. 600).

3 Para perceber esse rigorismo de Kant, leia-se, além das páginas iniciais da Fundamentação da Metafísica dos Costumes, a continuação do parágrafo da segunda Crítica que começa dessa forma: “Oh Dever!..”. (KANT, 2002, p. 140). 
Crítica da Razão Prática: diante de um cidadão comum, no qual percebo uma retidão de caráter meu espírito inclina-se, quer eu queira, quer não. Por isso, "o respeito é um tributo que não podemos recusar ao mérito..". (KANT, 2002, p. 125).

Uma questão fundamental, aqui, é se a observantia não pode ser puramente vazia, ou seja, se não é possível respeitar as outras pessoas, como Kant escreve na Metafísica dos Costumes, simplesmente "a distância". Em seus próprios termos: "O amor pode ser visto como atração e o respeito como repulsão, e se o princípio do amor aproxima os amigos, o princípio do respeito exige que eles se mantenham a uma distância própria entre eles" (KANT, 1968, p. 609; itálicos acrescentados). Por isso, talvez alguém pense que seja possível respeitar uma pessoa de modo puramente negativo, simplesmente não infringindo os direitos dela, mas também não tendo nenhuma preocupação com o bem-estar dela, com a sua felicidade. Essa leitura "minimalista" de Kant também parece equivocada. Por exemplo, Marie von Herbert, numa carta a Kant datada de 1793, teria dito que faria duas vezes mais do que a moralidade kantiana exige. A Ética de Kant parece ter sido interpretada como se ela fosse composta apenas de deveres negativos perfeitos: não quebrar as promessas, não cometer suicídio etc. $\mathrm{O}$ respeito garantiria essa moralidade tal como ela tem sido defendida hoje por eminentes eticistas tais como Dworkin e Tugendhat.

Há, todavia, um certo mal entendido aqui. Num comentário a uma das máximas de ação na Fundamentação da Metafísica dos Costumes, Kant escreve que é um dever levar em consideração os fins das outras pessoas para que elas sejam realmente tratadas como fins-em-si, no sentido completo e positivo dessa ideia, isto é, que sejam de fato respeitadas. Em seus próprios termos: "Pois os fins do sujeito, que é fim em si mesmo, têm de ser também, tanto quanto possível, os meus fins, se aquela representação deve produzir em mim todo o seu efeito" (KANT, 2009 , p. 249). Como se pode perceber, a matéria das minhas máximas, a saber, os fins das minhas ações é limitada pela ideia de que o outro ser humano ou todo e qualquer ser racional em geral não é uma coisa, mas uma pessoa e não pode ser tratado simplesmente como meio limitando meu arbítrio e isso implica incrementar os seus fins. Em outros termos, 
a pessoa é o objeto do respeito (Achtung) não apenas negativamente. Claro que o dever de incrementar os fins das outras pessoas é um dever imperfeito (isto é, não causa culpa se não for praticado aqui e agora, em relação a esse indivíduo particular etc.), pois não se pode fazer pelas outras pessoas aquilo que elas próprias fazem naturalmente ou que elas próprias, indiretamente, têm que fazer. Valério, como bom kantiano, seja de esquerda seja de direita, certamente procurava incrementar os fins das outras pessoas mostrando-lhes, desse modo, respeito.

Ninguém está obrigado, todavia, a respeitar um outro indivíduo no sentido de mostrar uma alta estima (Hochachtung) (cf. KANT, 1968, p. 607). A lição que aprendi de Valério, então, foi a distinção entre Achtung (respeito) e Hochachtung (estima, apreço, consideração, respeito) e sua vinculação com a distinção entre observantia e reverentia. Desse modo, ninguém está obrigado a respeitar pessoa alguma no sentido de estimá-la. Como Kant deixa claro na Metafísica dos Costumes, o único tipo de reverência ao qual estou obrigado é à lei moral (reverere legem). A forma mais segura de mostrar verdadeiro respeito aos outros é, por conseguinte, reverenciar a lei moral. A reverentia à lei moral, mais do que um mero respeito no sentido de um sentimento de estima, por exemplo, de um filho pelo pai, de um aluno pelo professor Valério Rohden etc. é condição necessária e suficiente do valor moral de toda e qualquer ação moral ${ }^{4}$. Se ela pode ser descrita como um sentimento, trata-se de um sentimento ímpar, o único produzido pela própria razão pura como Kant aponta na Crítica da Razão Prática (2002, p. 124). Nesses termos, a reverência pela lei não é móbil da moralidade, mas o único motivo propriamente moral, a própria moralidade subjetivamente considerada ${ }^{5}$.

Nesses termos, que o respeito é definido na Crítica da Faculdade do Juízo: "o sentimento da inadequação da nossa faculdade para alcançar uma ideia, que é lei para nós, é respeito” (KANT, 1992, p. 153).

4 Stephen Darwall, inspirado nessa distinção kantiana, diferencia entre dois tipos de respeito: enquanto reconhecimento (recognition respect) e enquanto estima (appraisal respect) (DARWALL, S. The second-person standpoint. Massachusetts: Harvard University Press, 2006. p. 122-123).

5 Em traduções de língua inglesa, geralmente usa-se reverence para traduzir o termo alemão "Ehrfurcht", mas Valério preferiu "veneração" que aparece diferenciado de “Achtung" na segunda Crítica (KANT, 2002, p. 132). 
Neste sentido, o eventual respeito que sentimos pelas outras pessoas ou pela natureza é no fundo uma subrepção. Nos termos de Kant, o "[...] sentimento do sublime na natureza é respeito pela nossa própria determinação, que comprovamos num objeto da natureza por um certa subrepção (confusão de um respeito pelo objeto como respeito pela ideia da humanidade no nosso sujeito) [...]" (KANT, 1992, p. 153). Por conseguinte, o respeito pelas pessoas é, no fundo, apenas uma manifestação da reverentia à lei moral. Valério, então, defendia que não havia diferença fundamental entre observantia e reverentia e, num certo sentido, ele estava certo. Entretanto, disto não se segue que se possa reverenciar a lei moral cumprindo-a motivados pelo prazer.

Para Kant, nada pode (nenhuma inclinação, nenhum sentimento, nenhum prazer etc.) ser causa determinante da vontade a não ser unicamente a lei moral para que a ação tenha valor moral. Valério provavelmente qualificaria essa forma de entender a Ética de Kant como uma entre tantas outras "interpretações distorcidas da filosofia moral kantiana” (ROHDEN, 2005, p. 235). Mas nisso tenho uma discordância hermenêutica séria com Valério: não compartilho da tentativa dele de amenizar o rigorismo de Kant colocando acompanhado da lei moral "um prazer na determinação da razão prática” (ROHDEN, 2005, p. 235). De fato, para Kant, não pode haver algo antes da lei moral; nada a não ser a lei moral na determinação da vontade para que a ação tenha valor moral. A vontade boa não se deixa guiar pela lei moral e pelo prazer. A distinção entre moralidade e legalidade, na Fundamentação, é inequívoca a esse respeito: só há valor moral na ação se o senso de obrigatoriedade for o único motivo para cumprir a lei moral. As ações não podem ser apenas conforme ao dever, mas têm que ser cumpridas por dever para terem valor moral (KANT, 2009, p. 117). Essa distinção também é ressaltada na Crítica da Razão Prática (KANT, 2002, p. 131) e jamais foi abandonada por Kant.

No fundo, então, a chave interpretativa da filosofia de Kant, utilizada por Valério, deve ser buscada em outro lugar. Neste sentido, sugiro (e não passa de uma sugestão), infelizmente sem a oportunidade de poder ouvir uma resposta do homenageado, que ela é revelada nesta frase: "Na terceira Crítica, assim como na concepção lógica da Crítica da razão 
pura, Kant revela-se epicurista" (ROHDEN, 2005, p. 234). Voilá: se Valério Rohden tinha uma leitura epicurista de Kant, então ele era, de fato, um kantiano não ortodoxo, mas nem por isso menos digno de respeito.

\section{Referências}

DARWALL, S. The second-person standpoint. Massachusetts: Harvard University Press, 2006.

KANT, I. Die metaphysik der sitten. Frankfurt: Suhrkamp, 1968.

KANT, I. Crítica da razão pura. Tradução de Valério Rohden e Ugo Moosburger. São Paulo: Abril Cultural, 1980.

KANT, I. Crítica da faculdade de julgar. Lisboa: Casa da Moeda, 1992.

KANT, I. Crítica da razão prática. Tradução de Valério Rohden. São Paulo: Martins Fontes, 2002.

KANT, I. Fundamentação da metafísica dos costumes. Tradução com introdução e notas de Guido Antônio de Almeida. São Paulo: Discurso Editorial, 2009.

LEBRUN, G. Apresentação. In: ROHDEN, V. Interesse da razão e liberdade. São Paulo: Ática: 1981. p. 13-21.

ROHDEN, V. Interesse da razão e liberdade. São Paulo: Ática, 1981.

ROHDEN, V. Viver segundo a ideia de natureza. In: BORGES, M. D.; HECK, J. Kant: natureza e liberdade. Florianópolis: Ed. da UFSC, 2005. p. 233-248.

Recebido: 24/09/2011

Received: 09/24/2011

Aprovado: 11/12/2011

Approved: 12/11/2011 